\title{
Advanced patented protective nanomaterials and coatings
}

\author{
O. Figovsky*, D. Beilin, A. Leykin \\ Polymate LTD.-International Nanotechnology Research Center, Migdal HaEmek, Israel \\ *E-mail address: figovsky@netvision.net.il
}

\begin{abstract}
Review of the advanced patents in the field of corrosion resistant coatings and composite polymer materials by company Polymate LTD.-INRC (Israel) and its employees. The review includes patents used by the industry of several countries of Europe, USA, Canada and Asia.
\end{abstract}

Keywords: chemical resistant materials; polymeric materials for coatings; hybrid nonisocyanate urethane-epoxides; nanostructured hybrid oligomer composition; rubber-based compositions; organicmineral coatings

\section{INTRODUCTION}

Corrosion is a serious problem that industries around the world are facing every day. It can cost billions of dollars to maintain and replace aging infrastructure, with more than $\$ 450$ billion being spent annually in the United States. In addition to the financial costs, corrosion has caused serious injuries and several fatalities. This paper is devoted to the review of the advanced patents in the field of corrosion resistant coatings and composite polymer materials by company Polymate LTD.-INRC (Israel) and its employees created under supervision of acad. O. Figovsky [1].

\section{PATENTS}

RU Patent SU 1070144 A issued to O. Figovsky et al in 1980 [2] describes the composition for impregnation of concrete floors of industrial buildings providing the higher wear resistance of the floors at influence of mineral oils. This composition contains the epoxy oligomer - epoxy dimethylhydantoin resin (26-33 wt. \% epoxy groups), amine hardener aminophenol, water (as solvent) and in addition - acetone formaldehyde resin with the following ratio (wt. parts):

- epoxy dimethyl hydantoin resin

- aminophenol

- water

- acetone formaldehyde resin 
RU Patent SU 1381375 A1 issued to O. Figovsky et al in 1980 [3] proposes the method for evaluating the protective characteristics of polymeric coatings on metals. The essence of the subject invention is shown in Figure 1 below.

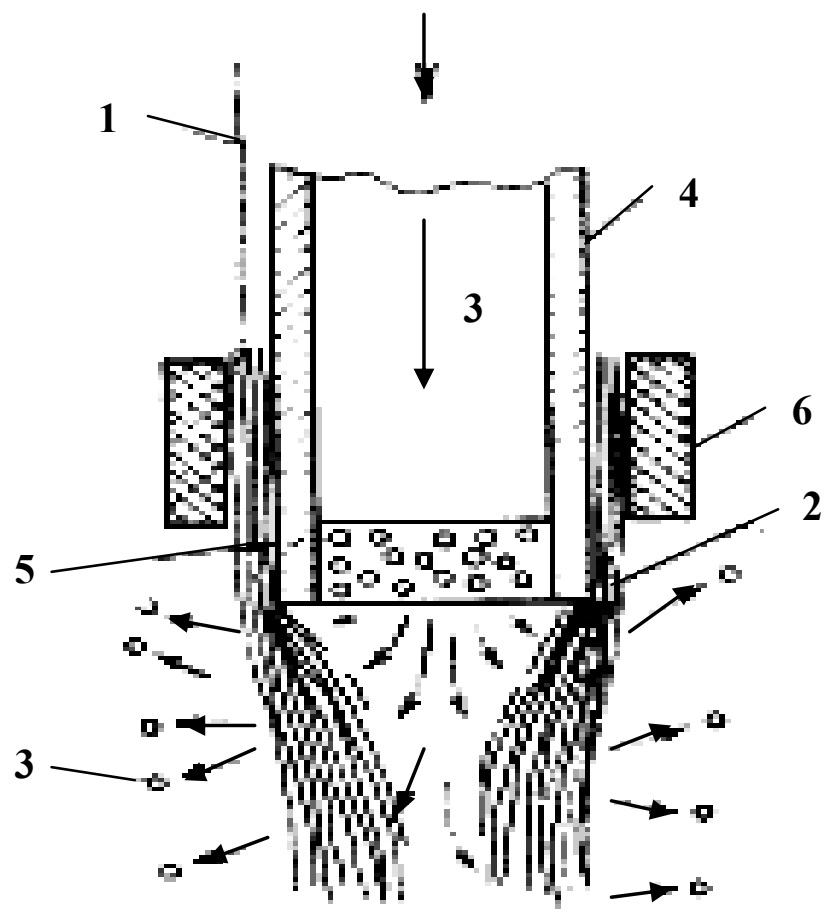

Figure 1. The essence of the subject invention.

A metal sample with a polymeric coating is placed into an agitated electrolyte with volume V. Indicator electrode system as a beam 1 of carbon threads 2 has the working surface $\mathrm{S}\left(\mathrm{cm}^{2}\right)$ corresponding to the condition $\mathrm{V}^{*} 10^{2} \leq \mathrm{S} \leq \mathrm{V} 10^{5}$. Sealing cup 6 is used for fastening of the threads 2 to a tube 4. Stirring of the electrolyte is provided by supplying of an inert gas 3 into the tube 4 with ceramic filter 5 . The evaluation of protective properties of a polymeric coating is carried out by measurement of the electroactive ions amount which have passed in electrolyte from under the coating.

An adhesive composition with improved corrosion resistance to copper, silver and other metals was proposed in US Patent 5,880,203 issued to L. Sklyarsky and O. Figovsky in 1999 [4]. The composition comprising mixture of a co-polymer of butylacrylate and acrylonitrile (said co-polymer being a cross-linkable clathrate matrix resin) and a second resin, said second resin being an olygodieneurethane resin with the end oxymethyloxazolidone groups and having general chemical formula 


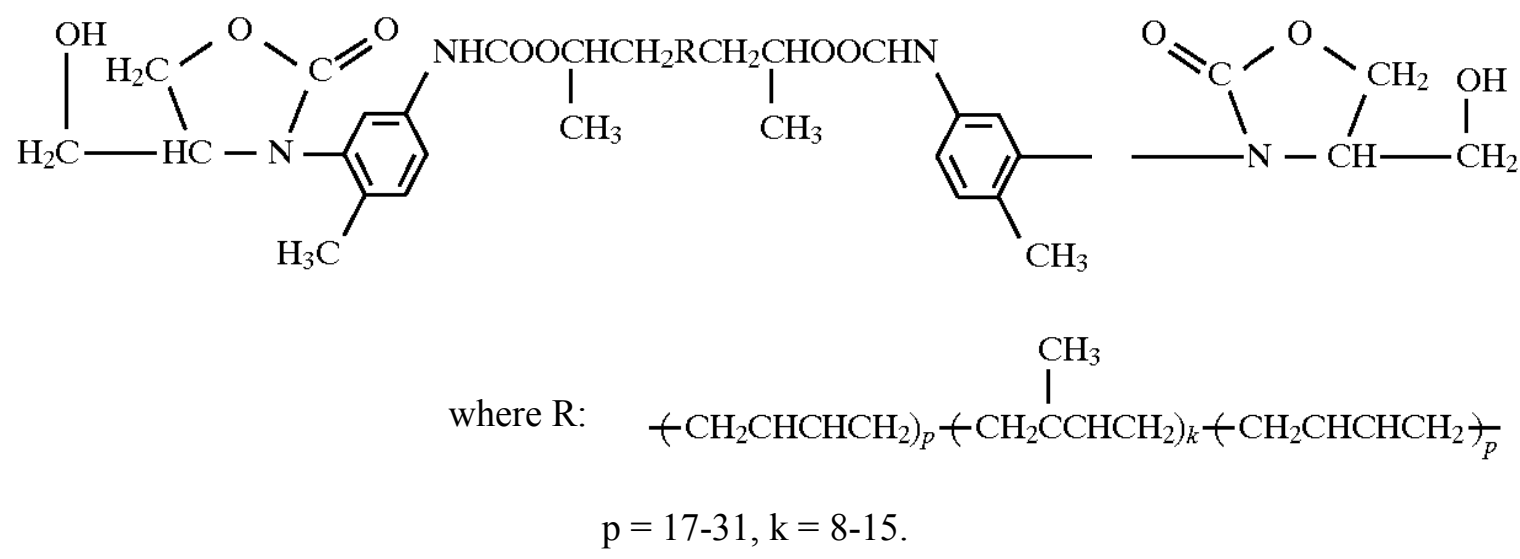

The composition also comprise of inorganic filler chosen from the group consisting of oxides, nitrides, carbonates (in particular it is $\mathrm{TiO}_{2}$ ) and of a cross-linking agent capable of cross-linking said co-polymer, said agent is a solution of a polyisocyanate, in particular it is a solution of triphenylmethane triisocyanate in dichloroethane, methylene chloride or ethyl acetate. The adhesive composition is used in electronic industry for securing various electrical radio and electronic components on a printed circuit board, a base plate, etc. as it is required during the manufacturing process. It is hardened at room temperature and has, besides corrosion resistance, improved adhering strength and thermal shock resistance.

Most inventions made by employees of Polymate INRC were devoted to polymeric materials for coatings based on hybrid nonisocyanate urethane-epoxides. A promising method was introduced in the form of a nonisocyanate urethane-epoxy polymer network with lower permeability and increased chemical resistance properties to aqueous solutions of acids and alkalis. Moreover, hybrid nonisocyanate networks are made by a synthesis process that uses far more environmentally benign materials than isocyanates and phosgene.

US Patent 6,120,905 issued to O. Figovsky in 2000 [5] relates to a hybrid nonisocyanate polyurethane network polymer formed by cross-linking at least one cyclocarbonate oligomer and at least one amine oligomer. The cyclocarbonate oligomer contains a plurality of terminal cyclocarbonate groups. At least one cyclocarbonate oligomer further comprises from about $4 \%$ to about $12 \%$ by weight of terminal epoxy groups. Because at least one cyclocarbonate oligomer contains both cyclocarbonate and epoxy reactive groups, the network formed therefrom is referred to as a hybrid nonisocyanate polyurethane network. The cyclocarbonate oligomer or oligomers have an average functionality towards primary amines of from about 2.0 to about 5.44. The amine oligomer comprises at least one primary amine-terminated oligomer terminated with primary amine groups and has an average functionality towards cyclocarbonate groups of from about 3.0 to about 3.8. The amine oligomer is present in an amount from about 0.93 to about 0.99 of the amount of the amine oligomer that would be required to achieve a stoichiometric ratio between the primary amine groups of the amine oligomer and the cyclocarbonate groups of the cyclocarbonate oligomer. The hybrid nonisocyanate polyurethane network polymer formed has a gel fraction of not less than about 0.96 by weight. These materials, in particular, are useful as nonporous monolithic coatings, coverings and linings, which can be used for the corrosion protection and wear protection of concrete, metallic and wood surfaces. 
In US Patent 6,407,198 issued to O. Figovsky et al. in 2002 [6] chemically resistant materials with high mechanical properties was provided by using polycyclocarbonates of special structure. The polycyclocarbonates were prepared by the reaction of oligocyclocarbonates containing ended epoxy groups with primary aromatic diamines. Such oligomers may be used by two ways - by curing the oligomers with primary aliphatic amines and by preparing adducts which are used for curing epoxy resins or cyclocarbonate oligomers for preparing chemically resistant coatings, constructive glues, sealants, etc.

US Patent 6,960,619 issued to O. Figovsky et al. in 2005 [7] describes a foamable photo-polymerized acrylic composition for use in variety of indoor or outdoor sealing and coating applications, where it is required to seal, to fill or to repair cracks, joints, gaps etc. in concrete, masonry, stone, wood or other constructional materials. The composition comprises acrylic based reactionable oligomers and it can be foamed and then polymerized while producing foam with structure suitable for sealing. Said acrylic composition was received with use of a product of reaction of nonisocyanate urethane diol with metacrylic or acrylic anhydride.

US Patent 7,232,877 issued to O. Figovsky et al. in 2007 [8] relates to a method and apparatus for synthesis of oligomeric cyclocarbonates from epoxy compounds and carbon dioxide in the presence of a catalyst. Also patent describes star epoxy compounds and their preparation and use in making star cyclocarbonates, star hydroxy urethane oligomers, and star NIPU and HNIPU, acrylic epoxy compounds, acrylic cyclocarbonates, acrylic hydroxy urethane oligomers, and acrylic NIPU and HNIPU and their methods of preparation. Coating on the base of these highly functionalized star compounds possess lower permeability and increased chemical resistance properties to aqueous solutions of acids and alkalis.

US Patent Application 20100144966 issued in 2010 [9] proposes a liquid oligomer composition that contains a hydroxyamine adduct and a liquid reacting oligomer. The hydroxyamine adduct includes an epoxy-amine adduct, which contains at least one primary amine group that is a product of the reaction of an epoxy compound with at least one terminal oxyrane group and at least one amine that contains at least two primary amino groups. In order to form the epoxy-amine adduct, 1 to 15 moles of at least one amine are reacted per equivalent of the aforementioned epoxy compound. The composition also contains at least one compound with one or more terminal cyclocarbonate groups. A method of manufacturing a liquid oligomer composition on the basis of the above compounds is also proposed. New nonisocyanate hybrid compositions are the base for high-solids oligomer coatings.

US Patent 7,820,779 issued to O. Birukov et al. in 2010 [10] discloses a nanostructured hybrid liquid oligomer composition including at least one epoxy-functional component (A), at least one cyclic carbonate component (B), at least one amine-functional component (C), and, optionally, at least one acrylate (methacrylate) functional component (D), wherein at least one epoxy, amine, or acrylate (methacrylate) component contains alkoxysilane units. The composition is highly curable at low temperatures (approximately 10 to $30{ }^{\circ} \mathrm{C}$.) with forming of nanostructure under the influence of atmospheric moisture and the forming of active, specific hydroxyl groups by reaction of cyclic carbonates with amine functionalities. According to the invention, the cured compositions, particularly coatings, have excellent resistance to weathering, solvents and abrasion, good appearance, strength-stress properties and adhesion to a variety of substrates. 
US Patent 7,989,553 issued to O. Birukov et al. in 2011 [11] describes a novel epoxyamine composition modified a hydroxyalkyl urethane, which is obtained as a result of a reaction between a primary amine $\left(\mathrm{C}_{1}\right)$ and a monocyclocarbonate $\left(\mathrm{C}_{2}\right)$, wherein modifier $(\mathrm{C})$ is represented by the following formula (1):

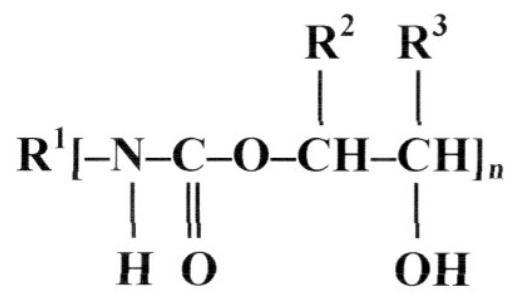

wherein $\mathrm{R}^{1}$ is a residue of the primary amine, $\mathrm{R}^{2}$ and $\mathrm{R}^{3}$ are the same or different and are selected from the group consisting of $\mathrm{H}$, alkyl, hydroxyalkyl, and $\mathrm{n}$ satisfies the following condition: $\mathrm{n} \geq 2$. Diluents, pigments and additives can be used. Doping with the hydroxyalkyl-urethane modifier imparts to the cured composition superior coating performance characteristics, such as pot-life/drying, strength-stress, bonding, appearance, resistance to abrasion and solvents, etc., in a well-balanced state.

US Patent Application 20120208967, issued to O. Birukov et al. in 2012 [12] proposes a method of producing hybrid polyhydroxyurethane network on a base of carbonatedepoxidized unsaturated fatty acid triglycerides. The method comprises: (a) reacting epoxidized unsaturated fatty acid triglycerides with carbon dioxide in the presence of a catalyst to obtain carbonated-epoxidized unsaturated fatty acid triglycerides, wherein conversion of oxyrane groups to 2-oxo-1,3-dioxolane groups (cyclic carbonate groups) for said carbonated-epoxidized unsaturated fatty acid triglycerides ranges from $35 \%$ to $85 \%$; (b) mixing and reacting the carbonated-epoxidized unsaturated fatty acid triglycerides with a compound having amine functionality comprising at least one primary amine group realized at stoichiometric or within nearly balanced stoichiometry; (c) mixing and reacting the product of step (b) with a compound having amine functionality comprising at least two primary amine groups realized at excess of an amine-functional compound; (d) subsequently mixing the product of step (c) with a compound having amino-reactive groups.

Another direction of the Polymate LTD.-INRC's investigations is liquid rubber-based compositions.

US Patent 6,303,683 issued to O. Figovsky in 2001 [13] relates to a synthetic rubberbased composition comprising: a low molecular weight rubber selected from polybutadiene comprising from about $75 \%$ to about $92 \%$ cis- 1,4 units, a copolymer comprising butadiene units and from about $27 \mathrm{wt} \%$ to about $45 \mathrm{wt} \%$ pentadiene units, and mixtures thereof, a high molecular weight rubber comprising isobutylene units and not more than about $6 \mathrm{wt} \%$ isoprene units, the high molecular weight rubber being present in an amount of from about 0.5 parts to about 4 parts by weight based on the weight of low molecular weight rubber, sulfur, a vulcanization accelerator, and an active filler where the sulfur, the accelerator, and the active filler are each present in the form of a powder within a particular particle size range(s). Additionally, these compositions may be used to form coatings and rubber 
concretes. The invention also relates to methods of producing such compositions, coatings and rubber concretes.

US Patent 7,989,541 issued to O. Figovsky in 2011 [14] discloses a synthetic-rubberbased composition that consists of a low-molecular-weight rubber selected from polybutadiene comprising about $75 \%$ to about $92 \%$ cis- 1,4 units, sulfur, a vulcanization accelerator, and an active filler wherein the sulfur, accelerator, and active filler are each present in the form of powder having a particular particle-size range. Additionally, the compositions comprise epoxy-terminated low number-average molecular weight rubber comprising butadiene-acrylonitrile copolymer with not less than 3 epoxy terminal groups per molecule. These materials may be used to form protective coatings such as anticorrosive coatings or chemically resistant rubber concrete. The proposed liquid composition can be combined with various organic and inorganic fillers and has improved properties and decreased cost as compared to known compositions. The invention also relates to a method of preparing the proposed composition.

One else direction of Polymate LTD.-INRC activity is organic-mineral coatings.

US Patent 6,329,059 issued to V. Karchevsky, et al. in 2001 [15] describes a polymeric composition having self-extinguishing properties which is useful as both an adhesive and coating. The composition contains $9-45$ weight percent of an organic polymeric component and 16-50 weight percent of quaternary ammonium silicate as a fire-retarding component. Fillers and hardening agents may also be a part of the self-extinguishing polymeric composition.

US Patent 6,337,036 issued to V. Karchevsky, et al. in 2002 [16] discloses a composition for use as a conductive coating for applying to various substrates. The composition has a particulate conductive component and temperature resistant component. The temperature resistant component contains an organic-mineral compound. The molar ratio of the conductive component to the temperature resistant component is (15-45):1, and the temperature resistant component is an aqueous solution of quaternary ammonium silicate having a silicate modulus of at least 4 and containing organic radicals with at least four atoms of carbon.

Some patents of the employees of Polymate Ltd.-INRC are devoted to corrosion resistance concrete.

RU Patent 2,135,425 issued in 1999 [17] discloses polymer concrete mix for chemically stable, highly strong building materials. Mix comprises low molecular cisoligodiene, low molecular diene oligomer of mixed microstructure, sulfur, thiuram, pyrite cinders, zinc oxide, calcium oxide, quartz sand, crushed granite stone. New material has greater bending and tensile strength.

RU Patent 2,185,346 issued in 2002 [18] describes organic concrete blend for manufacturing chemically stable high-strength parts and structures of building materials with improved consumer's properties. Blend contains, low-molecular polybutadiene, sulfur vulcanizing group (sulfur, thiuram, captax, zinc oxide, calcium oxide, diphenylguanidine, synthetic fatty acids), fly ash from heat- and-power stations, silica sand, and crushed granite. Due to such quantitative and qualitative selection of components, a possibility is enabled to prepare composite having advantages concerning workability as compared to known blends containing low-molecular diene oligomers, for instance hardening temperature is lowered from 125 to $90{ }^{\circ} \mathrm{C}$. Other characteristics of blend are on a level of those of known analogs. 
RU Patent 2,408,552 issued in 2006 [19] relates to composition of a nanostructuring binder for composite construction materials based on liquid glass and nanostructuring additives used for making acid resistant concrete, putty and other compositions. The nanostructuring binder for composite construction materials contains liquid glass, tetrafurfuryl ester of orthosilicic acid and a hardener. A portion of the liquid glass is replace with organic alkaline liquid glass containing an organic cation 1,8-Diazabicyclo[5.4.0] undec7-ene or 1,5-Diazabicyclo[4.3.0]non-5-ene. Use of the nanostructuring binder enables to increase acid resistance, water resistance and strength of construction materials and widens their field of use.

RU Patent Application 2011140460 A issued in 2011 [20] describes the polymer concrete composition including nonisocyanate polyurethane, fly ash, quartz sand and crashed stone with the following ratio (wt. parts):

- nonisocyanate polyurethane $8-16$

- fly ash 6-9

- quartz sand 25-28

- crashed stone 53-55

\section{References}

[1] O. Figovsky, A. Leykin, Nanoindustry 1(39) (2013) 8-12.

[2] A. Kuznetsov, O. Figovsky, I. Kim, V. Solomatov, SU Patent 1070144 A, Composition for impregnation of floors, 1980.

[3] A. Kuzmak, P. Agasyan, A. Kuteinikov, O. Figovsky, Yu. Zaharov, A. Kozheurov, $S U$ Patent $1381375 \mathrm{Al}$, The method for evaluating the protective characteristics of polymeric coatings, 1982.

[4] L. Sklyarsky, O. Figovsky, US Patent 5,880,203, Adhesive composition, 1999.

[5] O. Figovsky, US Patent 6,120,905. Hybrid nonisocyanate polyurethane network polymers and composites formed therefrom, 2000.

[6] O. Figovsky, L. Shapovalov, N. Blank, F. Buslov: US Patent 6,407,198, Cyclocarbonate groups containing hydroxyamine oligomers from epoxycylclocarbonates, 2002.

[7] O. Figovsky, L. Shapovalov, R. Potashnikov, Yu. Tzaid, J. C. M. Bordado, D. Letnik, A. De Schrijver, US Patent 6,960,619, Foamable photo-polymerized composition, 2005.

[8] O. Figovsky, L. Shapovalov, US Patent 7,232,877, Preparation of oligomeric cyclocarbonates and their use in nonisocyanate or hybrid nonisocyanate polyurethanes, 2007.

[9] O. Birukov, D. Beilin, O. Figovsky, A. Leykin, L. Shapovalov, US Patent application 20100144966, Liquid oligomer composition containing hydroxylamine adducts and method of manufacturing thereof, 2010.

[10] O. Birukov, D. Beilin, O. Figovsky, A. Leykin, L. Shapovalov, US Patent 7,820,779, Nanostructured hybrid oligomer composition, 2010.

[11] O. Birukov, O. Figovsky, A. Leykin, L. Shapovalov, US Patent 7,989,553. Epoxy-amine composition modified with hydroxyalkyl urethane, 2011. 
[12] O. Birukov, O. Figovsky, A. Leykin, R. Potashnikov, L. Shapovalov, US Patent Application 20120208967, Method of producing hybrid polyhydroxyurethane network on a base of carbonated-epoxidized unsaturated fatty acid triglycerides, 2012.

[13] O. Figovsky, US Patent 6,303,683, Liquid ebonite mixtures and coatings and concretes formed therefrom, 2001.

[14] O. Figovsky, US Patent 7,989,541, Liquid solventless synthetic-rubber-based composition, 2011.

[15] V. Karchevsky, O. Figovsky, F. Romm, L. Shapovalov, US Patent 6,329,059, Polymeric composition having self-extinguishing properties, 2001.

[16] V. Karchevsky, O. Figovsky, F. Romm, O. Aksenov, Z. Fiskin, A. But, US Patent 6,337,036, Conductive composition having self-extinguishing properties, 2002.

[17] Yu. Potapov, Yu. Borisov, O. Figovsky, RU Patent 2,135,425. Polymer concrete mix, 1999.

[18] Yu. Potapov, Yu. Shutilin, Yu. Borisov, V. Chmykhov, E. Savchenko, A. Polykutin, D. Panfilov, O. Figovsky, A. Samotsvetov, A. Mamonova, N. Trojnina, RU Patent 2,185,346, Organic concrete blend, 2002.

[19] D. Beilin, Yu. Borisov, O. Figovsky, I. Surovtsev, RU Patent 2,408,552, Nanostructuring binder for composite construction materials, 2011.

[20] Yu. Borisov, A. Anisimov, O. Figovsky, RU Patent Application 2011140460 A, Polymer concrete composition, 2011. 